\title{
Means Testing Adult Social Care in England
}

\section{Open}

\section{Les Mayhew}

Faculty of Actuarial Science and Insurance, Cass Business School, City, University of London, 106 Bunhill Row, London EC1Y 8TZ, UK.

E-mail: lesmayhew@googlemail.com

With the number of U.K. citizens aged 75 and over doubling to 10 million by 2040, social care funding remains a key policy challenge. The Care Act 2014 included reforms designed to make care funding sustainable, by establishing a new level for what individuals and the state will pay in England. However, the Government has postponed their introduction until 2020 amid concerns about cost. This paper uses the delay to investigate the current and proposed means testing formulae and finds fault with both. It proposes an alternative formula called the "preferred formula", which it argues is fairer and does not require capital limits. It further suggests that the proposed life-time cap care on costs is unnecessary since the preferred formula contains a mechanism that automatically limits asset depletion. Using examples, the research tackles an issue with all means testing which is that it disincentivises saving, so preventing more money entering the care system.

The Geneva Papers (2017) 42, 500-529. doi:10.1057/s41288-016-0041-0

Keywords: social and long-term care; demographic ageing; state support; means testing

The online version of this article is available Open Access

Article submitted 31 January 2016; accepted 19 December 2016; published online 10 April 2017

\section{Introduction}

How best to fund adult social care remains both topical and controversial, especially following the Government decision to postpone the implementation of proposed new funding arrangements until 2020 amid concerns about cost. This research calls for a simplified approach to means testing which would still be linked to a person's ability to pay, but it would include incentives to set aside money for care in the knowledge that it would not be simply taken away by an equivalent reduction in state support. The paper deals specifically with the care system in England contained in the Care Act (2014). ${ }^{1}$ Devolved systems in Northern Ireland, Wales and Scotland, although essentially based on the same principles as in England, contain important differences. However, a detailed discussion of their arrangements is beyond the scope of this paper. ${ }^{2,3,4}$

Means testing is a form of insurance or "safety net" providing financial assistance or a financial waiver to people whose income falls below some norm or standard which is

\footnotetext{
${ }^{1}$ http://www.legislation.gov.uk/ukpga/2014/23/contents/enacted/data.htm.

${ }^{2}$ Northern Ireland: https://www.nidirect.gov.uk/articles/paying-your-residential-care-or-nursing-home-fees.

${ }^{3}$ Wales: http://gov.wales/topics/health/socialcare/care/?lang=en.

${ }^{4}$ Scotland: http://gov.wales/topics/health/socialcare/care/?lang=en.
} 
applied to many areas of public spending. These include eligibility for free or subsidised goods or services, such as medical prescriptions, school meals, help with tuition fees, social housing and many others. ${ }^{5}$ The main alternatives to means testing are universal provision, such as the National Health Service or social or private insurance. This paper does not challenge the fundamental principle of means testing but argues that there is a better way than the current proposal to replace the present system. ${ }^{6}$

It reviews the current and proposed approaches to providing financial support for social care. It goes on to suggest a different way of treating income and assets more logically and fairly and, in doing so, it replaces a complex jumble of limits and thresholds. Although technical details are similar, it will be argued that the principles underpinning the preferred method are easier to grasp with fewer administrative costs. Using worked examples, the paper proposes ways in which savers could be rewarded without necessarily losing all of their entitlement to state support. It is further argued that its effect will be to bring in much needed new money into an increasingly cash-starved system.

\section{Social care in an ageing society}

Unfortunately, terminology can vary between countries. In this paper, the term "social care" is used as an umbrella term that includes all forms of formal and informal care and subsumes long-term care which usually refers to care provided in a residential or nursing home. Our focus is on the mainly retired population aged 65+ rather than on younger adults with care needs who are least likely to be able to fund themselves. These groups who have led normal working lives will have accumulated wealth and pension entitlements and so are expected to make a contribution towards their care needs in future years.

The problem of how to pay for social care has been revisited many times in recent decades, but the passing of the Care Act (2014) is generally reckoned to be an important milestone in this process. Nobody can doubt the urgency for reform. With the number of U.K. citizens aged 75+ doubling to 10 million by 2040, and with 1.3 million people already receiving social care services in England alone, the demand for long-term care is expected to increase significantly in coming decades. ${ }^{7}$

Responsibility for providing care is split between the individual and the state with the state acting as a provider of last resort. By making care free or fully privatised, either taxes or out-of-pocket costs could sky rocket and so state support needs to be carefully calibrated to avoid either from happening. However, it is chance what kind of care will be required in later life and so it is both difficult and expensive to protect against. For example, it could range from a few days spent at home to years spent in residential or nursing care, and so it is difficult to predict or quantify.

The problem is also a major policy issue in other ageing societies but often from different perspectives. ${ }^{8}$ Helping those in the greatest need and least able to support

\footnotetext{
${ }^{5}$ National Audit Office (2011).

${ }^{6}$ http://www.legislation.gov.uk/ukpga/2014/23/contents/enacted/data.htm.

${ }^{7}$ Appleby (2013); Mayhew et al. (2010); Wittenberg et al. (2008a, b); Karlsson et al. (2007); Forder (2007); Karlsson et al. (2006a, b).

${ }^{8}$ For example, see Colombo et al. (2011); Pickard et al. (2007); Costa-Font et al. (2008); Karlsson et al. (2007); Comas-Herrera et al. (2006).
} 
themselves is especially ingrained into the U.K. welfare system but so is self-reliance. ${ }^{9,10}$ Although Karlsson et al. ${ }^{11}$ showed that the U.K. has one of the lowest-cost systems of social care among its economic peers, this could be construed in two ways: (a) it is underfunded or (b) it is highly efficient. This research thinks that (a) rather than (b) applies because of the way means testing works in practice.

\section{Recent reforms}

In England, some important decisions have already been taken about the future of social care following the passing of the Care Act. This has placed new duties on municipalities (i.e. local authorities) to undertake entirely separate individual care and financial means assessments. Before the Care Act needs assessments were based on the Fair Access to Care System (FACs) in which there were four bands-critical, substantial, moderate and low. ${ }^{12}$ This allowed for an element of discretion as to whether a local authority would fund care needs or not depending on which band they were in.

Under the Care Act, FACs have been replaced a national minimum eligibility threshold broadly equivalent to "substantial" alongside a new system of funding and charging. ${ }^{13}$ This would remove one of the idiosyncrasies of the present system resulting from local discretion in which one municipality may grant eligibility for financial support and another not. Under the new arrangements, local authorities must carry out an assessment of anyone who appears to require care and support, regardless of their likely eligibility for statefunded care. Once the needs assessment is complete, a financial assessment is made, known as a "means test", to see if a user qualifies for state financial support.

Implementation of the new system of state financial support, which includes changes to the capital limits, has been delayed to 2020 and so eligibility under the present system remains as it has been for the time being. If a user has assets over $£ 23,250$, they are assessed as being able to meet the full cost of their care, but, if they are below $£ 14,250$, they are protected. For capital between these two limits, a contribution of $£ 1$ per week for every $£ 250$ of capital is required. This is termed "tariff income" in the regulations and is meant to represent the amount that individuals should be able to contribute from their own resources aside from their usual income.

Under the proposed system, there will be a life-time cap on care costs. Everyone with eligible needs will have a care account that will record their progress towards the cap and once reached, future care costs would be met by the state. After due consideration, the Government set the "life-time cap" at $£ 72,000$ which would then rise in line with inflation. Whether care is provided in the user's home or in residential care, only the rate set by the municipality will count towards the cap. Note that the cap does not cover daily living costs, which could more than double the outlay, although these costs would normally be incurred

\footnotetext{
${ }^{9}$ Commission on the Future of Health and Social Care in England (2014); Colombo et al. (2011); Poole (2006); Wanless (2006); HMSO (1999).

${ }^{10}$ See also Select Committee on Public Service and Demographic Change (2013).

${ }^{11}$ Karlsson et al. (2007).

12 See Social Care Institute for Excellence (SCIE), Fair access to care services (FACS): prioritising eligibility for care and support, www.scie.org.uk/publications/guides/guide33/changing-scene/eligibility-criteria.asp (accessed 12 Feb 2014).

13 SCIE (2015).
} 
anyway. ${ }^{14}$ The rationale for the cap is twofold: firstly to avoid some people incurring what the Commission on Funding Care and Support termed as "catastrophic care costs" and secondly, to make it simpler for insurance companies to introduce insurance policies which would provide protection up to the cap. ${ }^{15}$

To give an example, if the care cost element is say $£ 12,000$ p.a., then a person would need to be in care for 6 years for it to be triggered. This is higher than typical durations of care in residential settings, so it only provides protection for those with assets above this level. If they are cared for at home and their care needs are fewer, the time taken to reach the cap will be correspondingly greater and therefore its effect would be arguably nugatory. ${ }^{16,17}$ It is worth noting that the Commission on Funding Care and Support recommended a cap of $£ 35,000$ rather than $£ 72,000$ which would have allayed this tendency. However, it is argued that the cap will at least give certainty and peace of mind to the maximum of how much people will be asked to pay towards their care.

The problem is that the cap is not particularly easy to implement because it requires new administrative machinery to monitor individual care accounts. In addition, the hoped development of insurance products has not happened in practice. Questions remain over how the cap will work as care needs change over time requiring case reviews and reassessments. The Act also creates a requirement to provide assessments to people that would not have been eligible for state support because they were self-funders, so increasing the scope and coverage of the new system. In this paper, we therefore ask the question whether the cap serves any practical purpose given the administrative overheads involved, the fact that many will never reach it in their life-times, and that no insurance market has emerged.

Means testing under the proposed system will be similarly based on the present system, i.e. taking both assets and income into account. The key difference with the present system is changes to the capital limits. The Government has proposed a new upper limit of $£ 118,000$ and a limit of $£ 27,000$ for people where the value of their home is disregarded (e.g. for domiciliary care or where the spouse continues to live in the home). The new lower capital limit is $£ 17,000$ (previously $£ 14,250$ ) is designed to protect some of a person's assets. Whilst the new limits are plainly more generous, they are also arguably more complicated to administer (for example, independent asset valuations may be required). However, it is not our intention in this paper to enter into the detail about the types of asset definitions covered by the proposed system and which qualify or not.

Suffice it to say that for most people their home is the most important asset. Indeed, a key aim of the Dilnot Commission was to consider how homes could be better protected. A home is not counted as capital if certain people still live there such as a husband, wife, civil partner, close relative or carer. Neither is it counted as capital if care is being delivered to a person in their own home. In certain circumstances, the home must be sold to pay for care, although under new arrangements repayment of care fees can be postponed until after death. Detailed rules for the treatment of different kinds of assets including investment

\footnotetext{
${ }^{14}$ Kenny et al. (2016).

15 Commission on Funding of Care and Support (2011).

${ }^{16}$ Note that a different system operates in Scotland. Free personal and nursing care is available for everyone aged 65 and over who have received an assessment.

${ }^{17}$ In more limited circumstances, care may be provided completely free of charge under the so called "continuing care system' provided by the NHS but we do not discuss this further here.
} 
bonds with a life insurance component, their beneficial ownership and rules governing the definition and treatment of income other than earnings may be found in CRAG and are not discussed further here. ${ }^{18,19}$

\section{Aims of the paper}

As far as financial assessments are concerned, there are several unresolved problems with the proposed system which are carried forward from the present system. One is a common perception that care costs, like health care, are provided for free and so it would be a waste of money to save for something the Government will pay for anyway. This belief is reinforced because people with higher incomes find that their support is taken away on a pound-for-pound basis. A wider consequence of this effect is that the flow of much needed new money into the social care system is arguably undermined as a result.

Although difficult to avoid in practice, the complexity of the test is also unhelpful. Arbitrary thresholds in the system create perverse incentives for people to spend down assets so that they are inside the relevant boundaries for financial support. Many also find the terminology is confusing, for example, the use of the word "tariff" to impute a notional income on assets is easily confused with everyday usage as a "pricelist" or tax on goods. In this paper, we use the word "tariff" to mean the nationally recommended cost of a particular care package rather than as a kind of "tax". There is no exact equivalent of a tariff in the current system, because arrangements are negotiated locally with providers. We use the word "taper" to describe how financial support is withdrawn as income increases (i.e. similar to usage in the U.K. tax and benefit system).

We will not be concerned here with the wider question of how the formula should operate, although it is important that financial assessments are undertaken as quickly as possible, and we support the case for a respite before care charges are levied as, for example, would apply in the case of intermediate care. ${ }^{20}$ This would have the beneficial effect of allowing preventive action to be taken in cases that would otherwise lead to an avoidable hospital admission or to accelerate transfer into residential care following a spell in hospital once a person's condition is stabilised. ${ }^{21}$

With this in mind, the aims of this paper are to present and evaluate different methods of means testing, in particular how to

- create a means test that can be used both for domiciliary and institutional care with equal clarity;

- make the system fairer and more transparent, e.g. by removing "cliff edges" which cause perverse behaviours such as the deliberate disposal of assets;

- treat people with similar personal wealth but split differently in terms of income and assets equitably and fairly;

\footnotetext{
${ }^{18}$ Department of Health (2014) Charging for Residential Accommodation Guide (CRAG): https://www.gov.uk/ government/uploads/system/uploads/attachment_data/file/301250/CRAG_34_April_2014.pdf.

${ }^{19}$ See Age UK (2015, August) Factsheet 10_Paying for permanent residential care, http://www.ageuk.org.uk/ Documents/EN-GB/Factsheets/FS10_Paying_for_permanent_residential_care_fcs.pdf?dtrk=true\%5D.

${ }^{20}$ A more radical proposal could be to separate means testing from care needs assessments e.g. as part of the tax system.

${ }^{21}$ Mayhew and Lawrence (2006); Mayhew (2009).
} 
- simplify the rules so that anybody could reasonably be expected to undertake their own assessment with minimal financial expertise or using the Internet; and

- bring new money into the system, primarily private, from individuals and not the state by providing the appropriate incentives to save.

In the following sections, we provide an overview of the present and proposed means testing system and signpost wherein lie the main problems. We then describe and evaluate a new formula for means testing, which we compare with the proposed system and highlight important differences. Thirdly, we subject both the new and proposed formula to different scenarios to show how much it would cost and what entitlements would be over a typical care cycle. In doing so, we support this with stylised but realistic examples involving both residential and domiciliary care. A further section considers the role of financial incentives to encourage people to save for care.

\section{Present system for means testing social care}

Ideally, local authorities must offer each user a choice of at least one care home that not only is affordable but also to be able to choose alternatives including more expensive accommodation, e.g. where a third party contributes towards the cost. ${ }^{22}$ The amount a person pays towards the cost will depend on their capital and income. If assets are over $£ 23,250$, they are assessed as being able to meet the full cost of their care and so receive nothing. If it is between $£ 14,250$, the lower limit, and $£ 23,250$, this is considered as providing a person with $£ 1$ a week for every $£ 250$ of their capital. This equates to a person's assets $\times 52 / 250$ p.a. or equivalently assets $\times 0.208$.

If a person is in a residential institution, he or she is allowed to keep $£ 24.40$ a week of their income for personal use (i.e. $£ 1,268.80$ p.a.). Later, we will assume that the personal allowance has been netted off income in order to simplify the exposition, although its retention is implicit in all that follows. For the sake of example, let us suppose that fees in the preferred care home are $£ 25,000$ p.a. and that this is $£ 5,000$ more than the municipal standard rate or care tariff for this type of care. Table 1 shows how the current system works for four people with different means.

Case A has savings of less than $£ 14,250$ and so there is no imputed income; Case A pays $£ 3,731.20$ and receives $£ 16,268.80$. Case B has savings of $£ 20,000$ which is between the lower and up capital limits and so is assessed as having an imputed income of $£ 1,196$ p.a.; B pays $£ 14,927.20$ and receives $£ 5,072.80$ from the municipality. Both A and B must also make a top-up payment to cover the difference between the tariff and care home fee.

Here, the top-up cost is often met by the person's family (or other third party) and not by the user, who is required to spend almost all of their income on the user charge. Cases $\mathrm{C}$ and $\mathrm{D}$ receive no contribution at all because C's income minus the personal income allowance exceeds the care tariff, and D because their savings are greater than the capital limit. Cases C and D are hence deemed to be "self-funders".

\footnotetext{
${ }^{22}$ Care and Support Statutory Guidance issued under the Care Act 2014, para. 8.33. https://www.gov.uk/ government/uploads/system/uploads/attachment_data/file/315993/Care-Act-Guidance.pdf.
} 
Table 1 How the present systems works with four examples of financial assessments (all figures except savings in £s p.a.)

\begin{tabular}{llcccc}
\hline Line & Basis for assessment & $A$ & $B$ & $C$ & $D$ \\
\hline 1 & Care home fees & 25,000 & 25,000 & 25,000 & 25,000 \\
2 & Municipal tariff or standard rate & 20,000 & 20,000 & 20,000 & 20,000 \\
3 & Income p.a. & 5,000 & 15,000 & 25,000 & 15,000 \\
4 & Personal expense allowance & $1,268.80$ & $1,268.80^{\mathrm{a}}$ & $1,268.80$ & $1,268.80$ \\
5 & Savings & 10,000 & 20,000 & 20,000 & 40,000 \\
6 & Imputed income p.a. & $0^{\mathrm{f}}$ & $1,196^{\mathrm{b}}$ & $\mathrm{n} / \mathrm{a}$ & $\mathrm{n} / \mathrm{a}$ \\
7 & Residents contribution & $3,731.20$ & $14,927.20^{\mathrm{c}}$ & 25,000 & 25,000 \\
8 & Municipal contribution & $16,268.80$ & $5,072.80^{\mathrm{d}}$ & 0 & 0 \\
9 & Top-up payment & 5,000 & $5,000^{\mathrm{e}}$ & Self-funding & Self-funding \\
\hline
\end{tabular}

${ }^{\text {a }}$ Personal expense allowance $=52 \times$ weekly allowance of $£ 24.40=1,268.80$.

b Imputed income p.a. $=($ savings - lower capital limit $) / £ 250 \times 52=(£ 20,000-£ 14,250) \times 0.208=£ 1,196$.

c Income - personal allowance + imputed income $=£ 15,000-£ 1,268.80+£ 1,196=£ 14,927.20$.

d Tariff - resident's contribution $=£ 20,000-£ 14,927.20=£ 5,072.80$.

e Actual care home fees - Tariff $=£ 25,000-£ 20,000=£ 5,000$.

$\mathrm{f}$ There is no imputed income to pay since savings are below $£ 14,250$.

In the case of domiciliary care, financial arrangements can vary enormously between municipalities and are not discussed here. However, in a worked example later, we show how a revised formula could work in domiciliary as well as residential settings. By any yardstick, this is a complicated process with several arbitrary features: firstly, the "cliff edge" such that if a person's assets exceed the $£ 23,250$ limit, state assistance is zero; secondly, the arbitrary value of imputed income based on $£ 1$ per week for each $£ 250$ of assets that fall between two arbitrary limits. Combined these rules significantly reduce any incentive to save for care or to set assets aside particularly for those at or near the $£ 23,250$ asset limit which becomes a psychological barrier as a result.

Inevitably there will be some "gaming" of the system-i.e. to stay below the prescribed upper capital limit. Clearly, the bigger the "cliff edge" the more gaming will occur. In practice, this is effectively tolerated as long as the amounts are small (e.g. a person divests themselves of say $£ 1,000$ worth of savings to get below the upper capital limit). If on the other hand, a person intentionally gifts their home shortly before they enter care, the system calls this a "deliberate deprivation of assets" and for assessment purposes, the person would be treated as still owning the asset.

\section{Proposed means test}

In case of any doubt about how the current test is viewed, Andrew Dilnot who led the Commission on funding social care described it as the "most stupid and worst means test that we have". ${ }^{23}$ In its report, the Commission proposed changes to the system that would eliminate this cliff edge by altering the capital limits to make the transition to self-funding smoother. As previously noted, the Government has since proposed a new upper limit of

${ }^{23}$ Andrew Dilnot made this statement in his presentation at a meeting held at the Kings Fund, London on 20th September 2011. 
$£ 118,000$, and a limit of $£ 27,000$ for those receiving domiciliary care or where the spouse continues to live in the house. The new lower capital limit is $£ 17,000$ (previously $£ 14,250$ ). However, as previously stated, the introduction of the new arrangements, including the cap, has been postponed until 2020 because of concerns about costs. ${ }^{24}$

It is evident that the proposed means test is more generous than previously and also more gradual in its effect. This is shown in Figure 1 which shows the means test boundary for assets ranging from $£ 0$ to $£ 118,000$ instead of $£ 23,250$ previously for the case of a person in residential care who has not reached the cap. For the purposes of this chart, "care tariff" is assumed to be $£ 25,000$ p.a. as previously, including both care and accommodation costs. We call the area labelled A the entitlement zone for state support and B the self-funding zone. For example, a person with no assets but an income of $£ 25,000$ would not receive any support and similarly a person with assets above $£ 118,000$ but no income.

Income from assets is imputed on the same basis as in the present system, i.e. $£ 1$ per week for each $£ 250$ of assets above the lower limit of $£ 17,000$. For reasons previously stated, we call this imputation factor a "taper" rather than a "tariff income" as it is still known. Note that a different taper would result in a smaller or larger entitlement zone but never exceeding assets of $£ 118,000$ or an income which is greater than the tariff. The entitlement formula is given below. As can be seen, it retains similar features to the present system, including the computation for imputed income.

$$
\begin{aligned}
\text { State support p.a. }= & \text { Care tariff }- \text { (income net of personal allowance } \\
& + \text { imputed income })
\end{aligned}
$$

where Care tariff $=$ standard rate for residential care including living costs and Imputed income p.a. $=($ capital - minus the lower capital limit $) \times 52 / 250$ (or 0.208$)$.

Because it tries to do more, the proposed means test is arguably more complicated. Also, the limits themselves remain arbitrary, with no particular rationale other than to protect public expenditure, which is, of course important (although it is true that the upper limit is close in size to half the average property value of a home). There are two abrupt changes of direction in zone A-one created by the upper capital limit of $£ 118,000$ and the other occurring when income is $£ 25,000$ which is caused by the $£ 17,000$ lower capital limit. We will argue in the next section that an "all-in-one" calculation is unencumbered by boundaries and so is less complex.

\section{Preferred means test}

Previous sections have explained why the current and proposed means tests remain problematic. In this section, we describe a new method of means testing which we call the "preferred" formula. It forms one of a family of possible means tests which vary depending on how income and assets are treated and includes the proposed test of the previous section as one of the cases (see Annex A). Below, we describe how the "preferred" variant works, illustrating its operation with worked examples.

\footnotetext{
${ }^{24}$ Letter from Alistair Burt, the then care minister, to the Local Government Association, 17 July 2015: https:// www.gov.uk/government/uploads/system/uploads/attachment_data/file/446309/Cap_on_care_acc.pdf.
} 


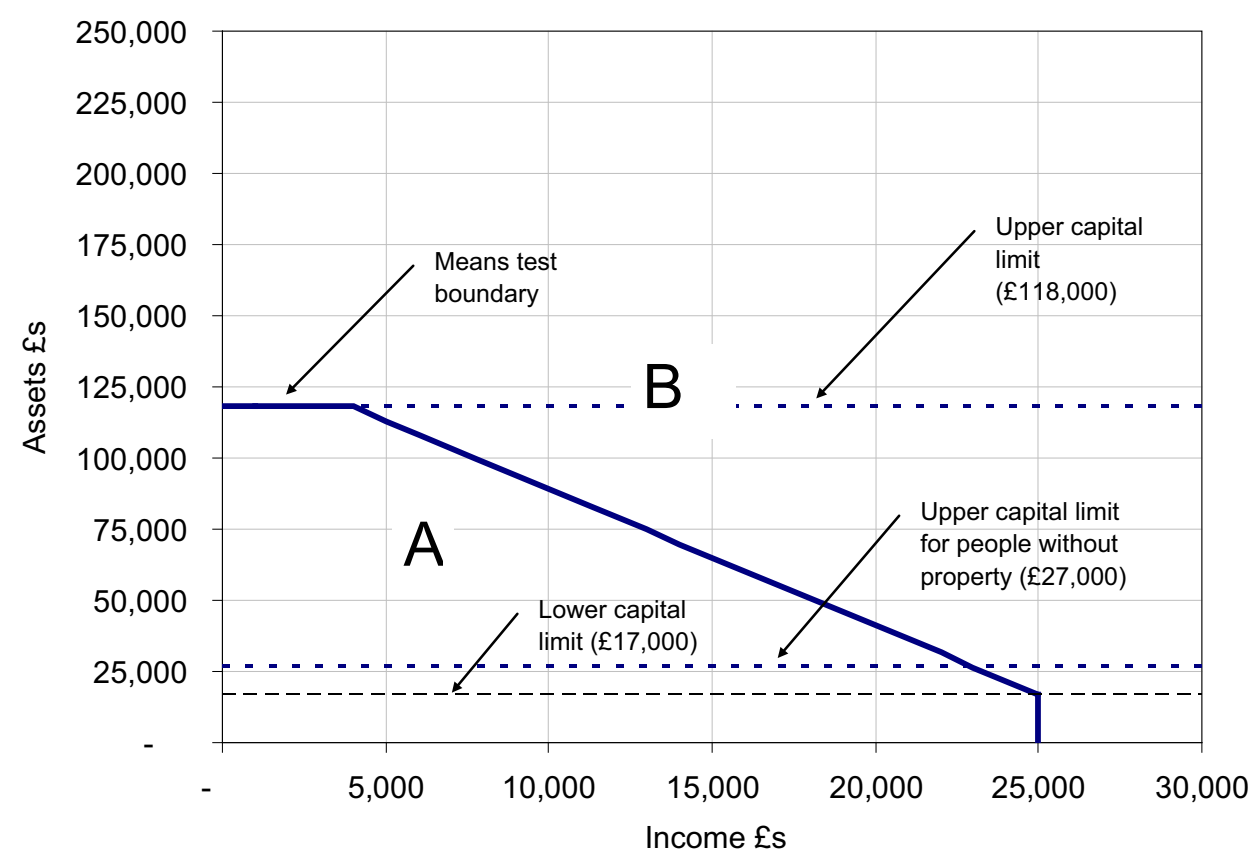

Figure 1. Proposed means testing entitlement zone for different levels of assets and income including upper capital limits for domiciliary and residential care and a lower capital limit.

Consider to begin with a care home with a tariff of $£ 25,000$ p.a. which includes both care and accommodation costs. The notional number of years a person with $£ 50,000$ in assets and an income of $£ 15,000$ p.a. (i.e. person D) could afford to pay for their care is $£ 50,000$ / ( $£ 25,000-£ 15,000$ ), i.e. 5 years before their capital is depleted. Annex A shows that the concept of affordable years is actually common to all means testing variants, although it has never been presented in this way before.

From the state's viewpoint, those who can afford more years of care receive less public support and vice versa. As with the current system, it means that if an individual selects a care home that is costlier than the tariff, then the top-up costs should come from a third party such as a relative. If a person's income equals or exceeds the tariff that person is deemed able to pay all care costs out of income alone. If care is not sustainable on income alone then assets will deplete over time and so how this operates becomes a key issue.

If their income is less than the tariff then individuals will be obliged to spend down their assets by an amount given in the formula below. Because the tariff sets an upper limit on what can or cannot be funded, there is arguably no need for an upper asset limit since funding is limited by the care package being provided and not by what care homes actually charge.

The formula is given by

$$
\text { Years of care afforded }=\text { Assets } /(£ 25,000-\text { annual income })
$$

The amount of support a person receives is given by

$$
\text { State support }=(1-\text { Taper } \times \text { Years afforded }) \times \text { Tariff }
$$


The taper varies between 0 and 1 such that the lower the taper, the more state support is provided. Note that what value the taper is set at is a policy issue and not a statistical artefact of the formula. For comparability with the proposed means test, we choose a factor of 0.2 , which essentially replaces the factor 0.208 in the current and proposed test. Application of the formula is undertaken annually to ensure that the eligibility and levels of support provided are regularly updated to deal with changes of circumstances.

Continuing with the previous example, the amount a person must pay towards their care in this case is $£ 25,000 \times 0.2 \times$ years afforded. In the formula, state support becomes zero when the term inside the brackets is zero or less, from which we can derive an upper asset limit that is linked to the tariff. If the level of support exceeds the difference between the tariff and income, the formula defaults to the lower of the two figures (i.e. the difference between the tariff and a person's income). This ensures that no one will receive more than the tariff.

Another way to think about the formula is given in Figure 2, which bands people according to the number of care years afforded. Those in Band A can afford up to 1 year, $\mathrm{B}$, between 1 and 2 years, C, between 2 and 3 years, D, between 3 and 4 years and E, between 4 and 5 years. Band A would receive between 80 and 100 per cent of their care costs, B 60 to 80 per cent, C 40 to 60 per cent, D 20 to 40 per cent and E 0 to 20 per cent. It follows from the formula that anyone with income at or above the tariff is deemed to be a "self-funder" because they can "afford" more than 5 years' worth of care from their income and assets.

It also can be deduced that in the theoretical case of a person having no income they would be eligible for financial support as long as their assets are $£ 125,000$ or less (i.e. 5 years of care at 25,000 p.a.). For taper values of $0.10,0.15,0.25$, say, upper asset limits would be $£ 250,000, £ 166,667$ and $£ 100,000$, in which case state support only kicks in if affordable years are less than 10, 6.67 or 4 years, this limit being given by one divided by the taper (e.g. $1 / 0.25=4$ years). For comparison, the taper in the proposed system 0.208 yields an upper limit of $£ 120,192$ (equating to 4.81 years) at this tariff, which is only slightly higher than the proposed upper eligibility limited for funding.

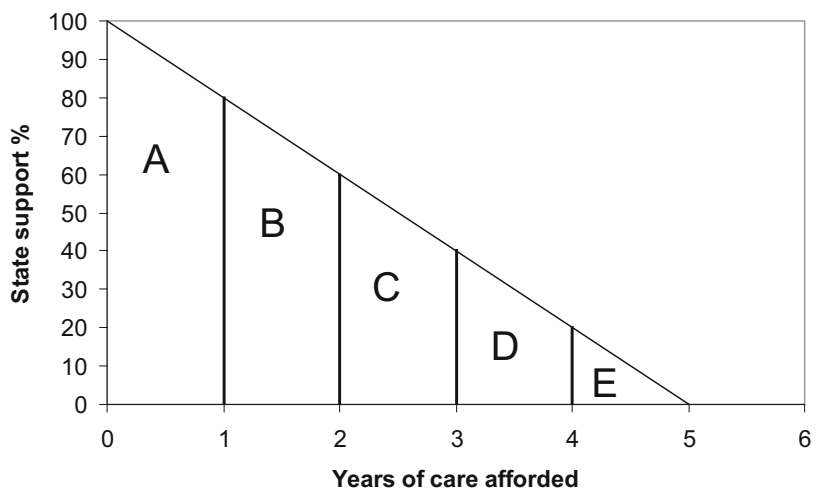

Figure 2. Preferred means test showing the levels of support for different care years afforded based on funding Bands A to E (see text). 


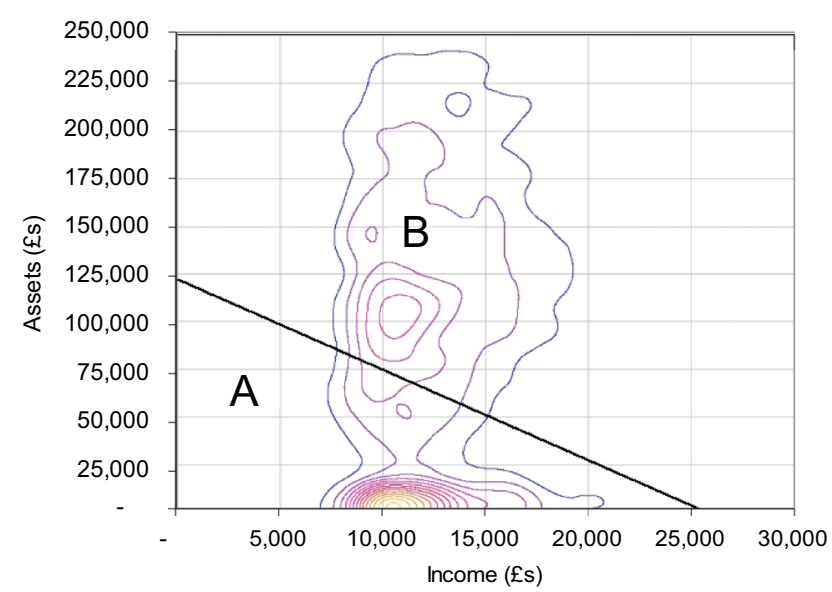

Figure 3. Simplified means test with contours showing concentrations of wealth in the $65+$ population. Assets include housing which is pro-rated according to ownership.

\section{Who is likely to benefit from state support?}

Figure 3 is a contour map showing the distribution of wealth in the $65+$ population-based income and assets including housing using data from ELSA. ${ }^{25}$ Contours represent actual concentrations of the $65+$ population with different levels of income and capital. By age 65 , most will have retired and so their incomes will generally be lower than in pre-retirement. It can be seen that income is concentrated in the $£ 7 \mathrm{k}$ to $£ 15 \mathrm{k}$ range, with a modal value of approximately $£ 11,000$ p.a. This is made up from a combination of the state pension, any occupational pension entitlement, plus other sources including welfare benefits.

The distribution of asset values shows a completely different pattern to income; it is bimodal (i.e. it has two peaks) and ranges from nothing to very substantial amounts (assets above $£ 250,000$ are not shown). ${ }^{26}$ Two particular asset concentrations are observed-one, very dense, near the $\mathrm{x}$-axis centred on incomes of $£ 11,000$ p.a. with assets of under $£ 25,000$, and another, centred on the same income, with assets of $£ 100,000$. This is because the second concentration is home owners and the first is not. Note that assets refer to individuals rather than couple households so that the value of jointly owned assets such as a home is divided equally in these cases.

The line sloping from left to right is the preferred means test boundary for state support based on a tariff of $£ 25,000$ and a taper of 0.2 which may be compared with the very crooked boundary, as shown in Figure 1. This follows directly from the preferred formula for state support in the previous section, which is zero when the taper $\times$ years afforded equals one. It cuts the $y$-axis when assets are worth $£ 125,000$ and income is zero, and the $\mathrm{X}$-axis when assets are zero and annual income is $£ 25,000$. Those located in area A qualify for state support and so are in the entitlement zone, and those in area B are self-funders.

\footnotetext{
${ }^{25}$ English Longitudinal Study of Ageing: http://www.elsa-project.ac.uk/ (accessed 12 Feb 2014). For couple households, housing assets are divided equally.

${ }^{26}$ Note that net negative assets are also possible, e.g. as a result of outstanding mortgage debt, although this is a relatively rare occurrence in this age group.
} 
Of the approximate $10 \mathrm{~m}$ people aged $65+$ in England, roughly $2.7 \mathrm{~m}$ people fall into category A and $7.3 \mathrm{~m}$ in category B before entering care. A comparison of Figure 3 with Figure 1 shows that entitlement zones are similar in size but there are now no cliff edges or boundary interruptions. Less expensive tariffs produce a smaller, nested set of parallel entitlement areas; since the tariff in this example is roughly what it would be for residential care, it will be among the highest. If the tariff were, say, $£ 20,000$ and not $£ 25,000$, it would cut the vertical axis when assets are $£ 100,000$ and the horizontal access, i.e. income at $£ 20,000$.

Our approach envisages that care tariffs would be graded according to need and includes an assessment for living costs as well as care. It is assumed that living costs for those receiving care at home would be informed by levels set in the social security benefits system. The tariff for entering a care home would be higher than for care provided in a person's home and would be divided into care and living costs as now. The highest tariffs would be reserved for people with the greatest needs and with other special circumstances such as dementia.

\section{Changes in financial circumstances and variations in levels of support}

Figure 4 shows how support under the preferred formula varies in the eligibility range, which is given by the hatched line in the bottom left corner based on a tariff of $£ 25,000$ and a taper of 0.2 . It shows that a person with no income or assets would receive $£ 25,000$, i.e. the maximum permitted; a person with $£ 5,000$ of income and no assets, $£ 20,000$ and so on. This taper provides some state support for anyone that has assets below $£ 125,000$ with no income and for anyone with no assets but an income of less than $£ 25,000$.

It is important for personal financial planning purposes to show how state support would alter if there is a change of circumstance, for example, a fall/rise in income or a fall/rise in assets. Income is more likely to remain unaltered than assets, although there may be opportunities to annuitise an asset or for assets to deplete over time in order to pay for care costs. From the formula, we can see that state support will change if either assets increase/ decrease or income increases/decreases or if there was a change in the tariff. This will depend on in the number of years afforded; if these go up, state support declines and vice versa.

The change is calculated by the following formula, which will generally apply as long as income is less than the tariff and provided support does not exceed the gap between the tariff and income.

\section{Change $=-$ Taper $\times$ Tariff $\times$ change in number of years afforded}

The percentage change is given by $\frac{-p \Delta Y}{(1-p Y)} \times 100$, where $\Delta Y$ is the change in the number of years afforded, $Y$ is the initial years afforded and $p$ is the taper.

In other words, the change in support is equal to minus the taper times the tariff times the change in affordable years. To give two examples: (a) if $Y$ increases by 1 year from 2 to 3 , the level of support would fall by $-0.2 \times 1 /(1-0.2 \times 2) \times 100=-33.3$ per cent; (b) if $Y$ falls from 3 to 2 years, the level of support would increase by $-0.2 \times$ $-1 /(1-0.2 \times 3) \times 100=50.0$ per cent. Other examples may be readily calculated. 


\begin{tabular}{|c|c|c|c|c|c|c|c|c|}
\hline \multirow{12}{*}{$\begin{array}{l}\infty \\
+\infty \\
\infty \\
\infty \\
\infty \\
\leftarrow\end{array}$} & $£ 250,000$ & $£ 0$ & $£ 0$ & $£ 0$ & $£ 0$ & $£ 0$ & $£ 0$ & $£ 0$ \\
\hline & $£ 225,000$ & $£ 0$ & $£ 0$ & $£ 0$ & $£ 0$ & $£ 0$ & $£ 0$ & $£ 0$ \\
\hline & $£ 200,000$ & $£ 0$ & $£ 0$ & $£ 0$ & $£ 0$ & $£ 0$ & $£ 0$ & $£ 0$ \\
\hline & $£ 175,000$ & $£ 0$ & $£ 0$ & $£ 0$ & $£ 0$ & $£ 0$ & $£ 0$ & $£ 0$ \\
\hline & $£ 150,000$ & $£ 0$ & $£ 0$ & $£ 0$ & $£ 0$ & $£ 0$ & $£ 0$ & $£ 0$ \\
\hline & $£ 125,000$ & $£ 0$ & $£ 0$ & $£ 0$ & $£ 0$ & $£ 0$ & $£ 0$ & $£ 0$ \\
\hline & $£ 100,000$ & $£ 5,000>$ & $£ 0$ & $£ 0$ & $£ 0$ & $£ 0$ & $£ 0$ & $£ 0$ \\
\hline & $£ 75,000$ & $£ 10,000$ & $£ 6,250$ & $£ 0$ & $£ 0$ & $£ 0$ & $£ 0$ & $£ 0$ \\
\hline & $£ 50,000$ & $£ 15,000$ & $£ 12,500$ & $£ 8,333$ & $£ 0$ & $£ 0$ & $£ 0$ & $£ 0$ \\
\hline & $£ 25,000$ & $£ 20,000$ & $£ 18,750$ & $£ 15,000$ & $£ 10,000$ & $£ 0$ & $£ 0$ & $£ 0$ \\
\hline & $£ 0$ & $£ 25,000$ & $£ 20,000$ & $£ 15,000$ & $£ 10,000$ & $£ 5$, & $£ 0$ & $£ 0$ \\
\hline & & $£ 0$ & $£ 5,000$ & $£ 10,000$ & $£ 15,000$ & $£ 20,000$ & $£ 25,000$ & $£ 30,000$ \\
\hline
\end{tabular}

\section{$£$ Income}

Figure 4. Implied state support based on a tariff of $£ 25,000$ and a taper of 0.2 for different levels of assets and income using the preferred formula.

\section{Equivalence of assets and income for a given tariff}

A general principle is that income and assets should serve a common purpose and be regarded as interchangeable as far as paying for care is concerned. However, a system of financial support in which assets receive more favourable treatment than income will tend to favour those whose wealth is skewed towards assets. The reason why this is important is that, not only is it unfair, but it will increase the effect of people seeking to gain an advantage on the state by shifting wealth between income and assets.

It is not possible to show strict equivalence based on trading assets for income since levels of support depend on the number of years of care afforded and also the tariff. However, it is possible to compare individuals not only with equivalent care needs but also wealth in terms of what their state support would be under the preferred and proposed methods. Table 2 gives three examples which compare state support at the point of assessment based on a tariff of $£ 25.000$. Each person has a different mix of assets and income, but each is notionally able to fund the same affordable number of years of care. In the preferred example, the taper is set at 0.2 and, in the proposed case, 0.208 .

Consider each person in turn. A has $£ 66,667$ of savings and $£ 5,000$ income p.a. Applying the preferred formula, Person A can notionally afford 3.33 years of care $(£ 66,667 /$ $(£ 25,000-£ 5,000)=3.33)$. Person $B$, with $£ 50,000$ of savings and $£ 10,000$ income p.a., 
Table 2 The amount of state support delivered by the preferred and proposed Government's means test for three people of equal wealth based on a tariff of $£ 25,000$

\begin{tabular}{llrccc}
\hline Person & Category & Amount $(£)$ & $\begin{array}{c}\text { Years of care } \\
\text { afforded }\end{array}$ & $\begin{array}{c}\text { Preferred } \\
\text { support }(£)\end{array}$ & $\begin{array}{c}\text { Proposed } \\
\text { support }(£)\end{array}$ \\
\hline A & Income & 5,000 & 3.33 & 8,333 & 9,669 \\
& Savings & 66,667 & & & \\
B & Income & 10,000 & 3.33 & 8,333 & 8,136 \\
& Savings & 50,000 & & & \\
C & Income & 15,000 & 3.33 & 8,333 & 6,603 \\
& Savings & 33,333 & & & \\
\hline
\end{tabular}

Note: Proposed support includes $£ 17,000$ asset lower limit.

can also afford 3.33 years of care $(£ 50,000 /(£ 25,000-£ 10,000)=3.33)$; Person $\mathrm{C}$ with $£ 33,333$ of savings and $£ 15,000$ income per annum, can also afford 3.33 years of care $(£ 33,333 /(£ 25,000-£ 15,000)=3.33)$. Under the preferred formula each therefore receives the same level of support, i.e. $£ 8,333$ (see second last column).

Under the proposed formula set out in the "Proposed means test" section, the levels of support would change. In comparison with the preferred case, A receives $£ 9,669$, B receives $£ 8,136$ and $C$, who has fewer savings than either $A$ or $B$, gets only $£ 6,603$. This difference between the cases is not caused by there being a different taper, although that affects the absolute amounts, but the way in which the formula works. Each extra pound of income results in an equivalent reduction in state support, but each extra pound in assets results only in a 20.80 pence reduction so having more wealth in assets than in income becomes advantageous.

To summarise, assets receive a more generous discount than income, with a $£ 3,066$ difference in the level of financial support between A and C. The asymmetric treatment of people with the same ability to pay for a given package of care thereby creates an anomaly if we are seeking to introduce a system which strikes a fair balance between individuals of similar means faced with the same care costs. The preferred formula gets around this problem.

\section{How long will financial assets last?}

An important concern to individuals entering into care is what will happen to their assets if their income is insufficient to cover the tariff. Under the proposed formula, the lower capital limit is $£ 17,000$; this amount is netted off during initial assessment and is therefore effectively protected from future changes in care needs. Each year a person's eligibility for state support is reassessed based on the tariff applying and on a person's remaining assets and income. The rate at which assets are run down is determined by the taper, which in the proposed case is 0.208 or 20.8 per cent p.a., as has been already noted.

How this works is set out in detail in Annex "Depletion of assets under the proposed formula" section. The example given is for a person with a residential care tariff of $£ 25,000$ p.a., of which $£ 12,000$ is care costs. Assuming initial assets of $£ 50,000$, by the time the cap is reached after 6 years, remaining assets above the lower limit would be 
worth 31 per cent of their original value (or $[£ 50,000-£ 17,000] \times 0.31=£ 10,230$ ). Total remaining assets will be $£ 10,283+£ 17,000=£ 27,283$, or 54.6 per cent of $£ 50,000$.

In contrast to the proposed formula, the lower limit in the preferred formula is not a single limit but one that depends on individual circumstances including the care tariff as well as a person's income. This makes sense because some people have more of their wealth in income and others in assets; in addition, some will have low tariffs and others high ones. In general, these limits are mostly higher than under the proposed formula, but they do not include the $£ 17,000$ which is netted off under the proposed formula. How the limits work in the case of the preferred formula and the computational details are set out in Annex "Depletion of assets under the preferred formula" section.

Limits in these cases do not apply to self-funders outside the entitlement zone, only to those eligible for state support. In other words, once their assets are run down sufficiently and state support is triggered, so the limit begins to take effect. Note that, this limit is never breached but is approached asymptotically over a period of time. As assets are depleted, the amount of state support increases until it equals the difference between the tariff and income. Note that if assets are already below the asymptotic limit, state support will already be at this level.

An example is given in Figure 5. Consider a person with initial assets of $£ 50,000$ with an income of $£ 10,000$. Assume, as before, the same residential tariff of $£ 25,000$ but with the preferred taper of 0.2 instead of 0.208 . The lower capital limit or asymptote under the preferred formula for this person is $£ 30,000$ based on the formula in Annex "Depletion of assets under the preferred formula" section and is based on annual assessment of the years of care afforded. Since the limit is independent of the amount of assets a person owns and only depends on the tariff, income and taper, the limit is always the same for any level of savings of over $£ 30,000$.

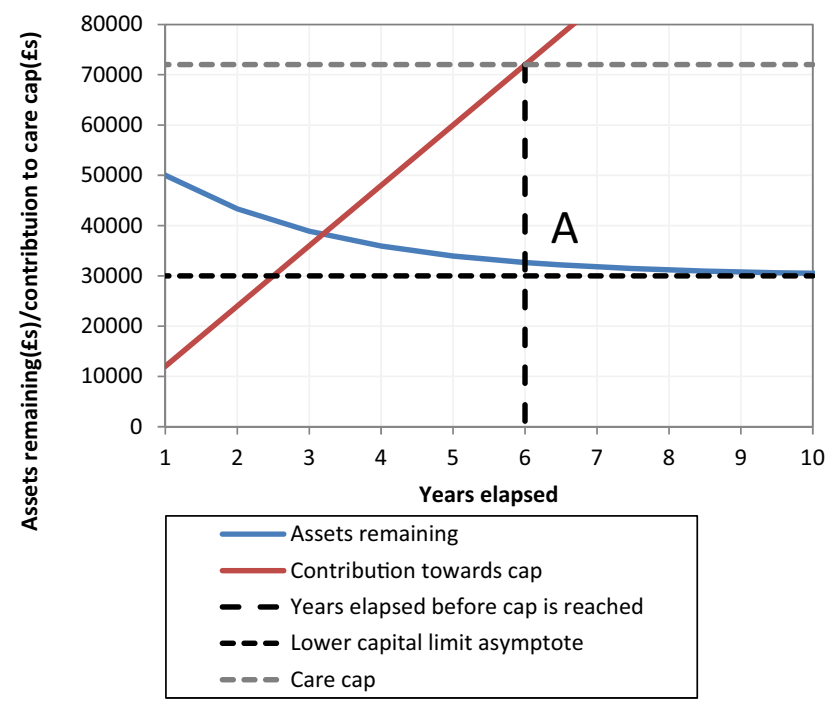

Figure 5. Asymptotic lower capital limit under the preferred formula (see text).

Note: vertical line at year 6 equates to the $£ 72 \mathrm{k}$ cap based on annual care costs of $£ 12,000$. Point A indicates assets remaining after cap is reached. 
Figure 5 also includes a line showing progress towards the $£ 72,000$ care cap which takes 6 years to reach (point A). It can be seen that the asymptotic limit of asset depletion is closely approached at more or less the same time as it takes to reach the cap. This is generally the case for a wide range of realistic examples and so it poses the interesting question of why a cap is needed, an issue to which we return in the "Concluding reflections" section.

In terms of the kind of limits to expect using the preferred formula, the lower capital limit will range from $£ 18,750$ to $£ 37,500$ based on simulations using a typical range of would-be tariffs. Annex "Depletion of assets under the preferred formula" section also shows the important result that the lower limit is a maximum when income equals half the tariff. The rationale is that people on low incomes but with large savings should be prepared to spend down more of their assets than people on average incomes, whilst those on high incomes that are nearer to the tariff require less asset protection.

A final observation on the use of the preferred formula in practice is its impact on the share of spending between the individual and the state over a defined period. We have seen that more assets are used in the first years than subsequently to pay for care, after which the state's share increases as is to be expected. In the next section, we bring these considerations together using worked examples showing how the share between the state and the individual changes over time in the preferred and proposed cases.

\section{Worked examples}

Two examples show how the transition from self-funding to state support might function in the first 6 years of care, assuming the individual to still be alive based on the preferred formula. The first is for a person entering a care home, and the second is a person receiving domiciliary care. The tariff in both examples is based on a combined assessment of the person's care needs and their living costs; but note that assessed living costs might differ from their actual living costs if they had remained at home.

To be clear, only the cost of care contributes to the care cap and so a person will continue to be liable for their living costs regardless of whether they hit the cap or not. If they are in institutional care, their assets will comprise their home, savings and any other eligible assets. The home is not included if there is a spouse or relative still living in their home or if the care is being delivered in a person's home instead (see domiciliary example below and earlier discussion on treatment of housing assets).

\section{Institutional example}

Table 3 gives the payment schedule for a hypothetical individual with a valid care assessment which entails residential-based care in which financial assessments are assumed to be carried out annually. It is designed to show the cost to a typical person who enters a care home and is initially self-funding. For the purposes of illustration, we again assume a care home tariff of $£ 25,000$ made up of $£ 12,000$ care costs and $£ 13,000$ living costs. To keep the example simple, we further assume that care needs are unchanged and hence the tariff does not change over time.

At the point of entry into the care home, the individual has $£ 100,000$ worth of assets and $£ 10,000$ p.a. income. Based on the preferred formula, it means that they are able to afford 6.7 years of care and so are not entitled to any support in the first year $(£ 100,000 /$ 
Table 3 Care cost progression over a six-year cycle for a person in a care home including the depletion of assets, state support and out-of-pocket costs based on a tariff of $£ 25,000$ and a lower asset limit of $£ 30,000$

\begin{tabular}{lccccccc}
\hline $\begin{array}{l}\text { Year in } \\
\text { care }\end{array}$ & $\begin{array}{c}\text { Cumulative } \\
\text { care payments } \\
(£)\end{array}$ & $\begin{array}{c}\text { Assessable capital } \\
\text { at start of care } \\
\text { year }(£)\end{array}$ & $\begin{array}{c}\text { State } \\
\text { support } \\
(£)\end{array}$ & $\begin{array}{c}\text { Cost to } \\
\text { individual } \\
(£)\end{array}$ & $\begin{array}{c}\text { Contribution } \\
\text { to cap }(£)\end{array}$ & $\begin{array}{c}\text { Years of care } \\
\text { afforded }\end{array}$ & $\begin{array}{l}\text { State } \\
\text { support } \\
\text { band }\end{array}$ \\
\hline 1 & 25,000 & 100,000 & 0 & 25,000 & 12,000 & 6.7 & Self-funder \\
2 & 50,000 & 85,000 & 0 & 25,000 & 24,000 & 5.7 & Self-funder \\
3 & 75,000 & 70,000 & 1,667 & 23,333 & 36,000 & 4.7 & E \\
4 & 100,000 & 56,667 & 6,111 & 18,889 & 48,000 & 3.8 & D \\
5 & 125,000 & 47,778 & 9,074 & 15,926 & 60,000 & 3.2 & D \\
6 & 150,000 & 41,852 & 11,049 & 13,951 & 72,000 & 2.8 & C \\
& Final balance & 37,901 & 27,901 & 122,099 & & & \\
\hline
\end{tabular}

$(£ 25,000-£ 10,000)=6.7)$ and nor in the second year when 5.7 years are afforded. Care costs counting towards the "care cap" are shown in the final column in which it is seen that the cap is reached after 6 years $(6 \times £ 12,000=£ 72,000)$. Although it is not approached in these examples, the lower asset limit for this case is $£ 30,000$ based on the formula in Annex "Depletion of assets under the preferred formula" section.

Column three shows the assets available at the start of the current year and column four shows that state support kicks in from year three. By the time the cap is reached the end of year six, the total cost to the state will be $£ 27,901$ and to the individual $£ 122,099$ (bottom row of table). At the start of year seven, the individual has $£ 37,901$ of savings remaining based on expenditure up to year six (i.e. $£ 41,852-£ 13,951+£ 10,000=£ 37,901$ ). Total expenditure to this point is $£ 150,000(£ 27,901+£ 122,099=£ 150,000), £ 60,000$ of which comes from income (40 per cent of the total), $£ 62,099$ from assets (41 per cent) and $£ 27,901$ (19 per cent) from state support.

In this time, the person moves from being a self-funder to Band $\mathrm{C}$ via Bands $\mathrm{E}$ and $\mathrm{D}$ (see final column and Figure 2). Note that if the individual is alive and remains in care beyond 6 years, then they are still liable for accommodation costs as these do not count towards the cap, so there may be further, smaller depletions of capital later on if living costs exceed income. In this example, assessed living costs are $£ 13,000$ and income is $£ 10,000$, so there would be an ongoing annual gap of $£ 3,000$. This would be met partly by state support and partly by personal assets until the lower asset limit is reached, which in this case is $£ 30,000$.

\section{Domiciliary example}

In this example, the person has savings worth $£ 50,000$ and receives care at home. The cared for person maintains control of their income, with state support usually being provided as part of an itemised integrated care plan or budget. This person has an income of $£ 10,000$ p.a. and an assessed home care tariff of $£ 18,000$ p.a. of which $£ 13,000$ is assumed to be living costs. In practice, the income needed for daily living will comprise a person's pension and other sources including entitlement to social security benefits. The municipality gives them an itemised personal budget over which they or their designated carer has control. For the first 2 years of care, this person is banded as a self-funder and so is ineligible for state support (see final column). 
As in the case shown in the "Institutional example" section, the level of state support gradually increases as assets decline and they move into Band E and then D. At the start of year seven, the individual has $£ 23,300$ in assets remaining (£24,182 - $£ 10,882+$ $£ 10,000=£ 23,300)$. Total expenditure to this point is $£ 108,000$ (£21,300+ $£ 86,700=£ 108,000), £ 60,000$ of which comes from income (56 per cent of the total), $£ 26,700$ from assets (25 per cent), and $£ 21,300$ (19 per cent) from means tested care support. As care costs accrue at the rate of $£ 5,000$ p.a., it will take this person 14.4 years to reach the cap assuming no change of tariff. By then, remaining assets will be very close to their asymptotic lower limit of $£ 22,222$.

\section{Out-of-pocket and state support costs compared}

A comparative evaluation of the proposed or preferred means tests involves judgements about how each performs in the same financial circumstances. This in turn will depend on values given to the taper and tariff in both formulae and to values given to the capital limits in the proposed test. A key difference between the two systems is that there is no mechanism in the proposed formula to prevent assets being run down indefinitely, which is why the $£ 17,000$ lower limit is required. One way is to compare costs to the state and the individual over the 6-year care cycle from the same initial starting positions in examples in the "Institutional example" and "Domiciliary example" sections.

How the proposed means test would fare against the preferred means test in these cases is shown in Table 5. The same parameters are used for assets and income in both, but $£ 17,000$ of assets are protected in the proposed case. The levels of support are seen to be very similar when compared over a 6-year period as shown in Tables 3 and 4; however, an important difference is that in the "Institutional example" section, the residential example, state support kicks in the second year; in the preferred test support, it is year three. In the domiciliary case in the "Domiciliary example" section, the levels of support and costs to the individual are also similar; here, state support commences in the first year in the proposed formula, and the third year in the preferred formula.

In answer to the broader question of which is the cheaper system to the tax payer (as opposed to the fairer system), the differences appear to be slight if compared over a reasonable

Table 4 Care cost progression over a six-year cycle for person receiving domiciliary care including the depletion of assets, state support and out-of-pocket costs based on a tariff of $£ 18,000$ and a lower asset limit of $£ 22,222$

\begin{tabular}{lccccccc}
\hline $\begin{array}{l}\text { Year } \\
\text { in } \\
\text { care }\end{array}$ & $\begin{array}{c}\text { Cumulative } \\
\text { care } \\
\text { payments } \\
(£)\end{array}$ & $\begin{array}{c}\text { Assessable } \\
\text { capital } \\
\text { at start of care } \\
\text { year }(£)\end{array}$ & $\begin{array}{c}\text { State } \\
\text { support } \\
(£)\end{array}$ & $\begin{array}{c}\text { Cost to } \\
\text { individual } \\
(£)\end{array}$ & $\begin{array}{c}\text { Contribution } \\
\text { to cap }(£)\end{array}$ & $\begin{array}{c}\text { Years of care } \\
\text { afforded }\end{array}$ & $\begin{array}{l}\text { State } \\
\text { support } \\
\text { band }\end{array}$ \\
\hline 1 & 18,000 & 50,000 & 0 & 18,000 & 5,000 & 6.3 & Self-funder \\
2 & 36,000 & 42,000 & 0 & 18,000 & 10,000 & 5.3 & Self-funder \\
3 & 54,000 & 34,000 & 2,700 & 15,300 & 15,000 & 4.3 & E \\
4 & 72,000 & 28,700 & 5,085 & 12,915 & 20,000 & 3.6 & D \\
5 & 90,000 & 25,785 & 6,397 & 11,603 & 25,000 & 3.2 & D \\
6 & 108,000 & 24,182 & 7,118 & 10,882 & 30,000 & 3.0 & D \\
\hline
\end{tabular}


Table 5 Levels of support delivered under the proposed formula applied to examples "Institutional example" and "Domiciliary example" in "Worked examples" section $($ Taper $=0.208)$

\begin{tabular}{lrccc}
\hline Year in care & $\begin{array}{c}\text { (a) Residential care } \\
\text { state support }(£)\end{array}$ & $\begin{array}{c}\text { (a) Cost to } \\
\text { individual }(£)\end{array}$ & $\begin{array}{c}\text { (b) Domiciliary care } \\
\text { state support }(£)\end{array}$ & $\begin{array}{c}\text { (b) Cost to } \\
\text { individual }(£)\end{array}$ \\
\hline 1 & 0 & 25,000 & 1,136 & 16,864 \\
2 & 856 & 24,144 & 2,564 & 15,436 \\
3 & 3,798 & 21,202 & 3,694 & 14,306 \\
4 & 6,128 & 18,872 & 4,590 & 13,410 \\
5 & 7,973 & 17,027 & 5,299 & 12,701 \\
6 & 9,435 & 15,565 & 5,861 & 12,139 \\
Final balance & 28,190 & 121,810 & 23,145 & 84,855 \\
\hline
\end{tabular}

period, in this case 6 years. However, it also depends on how long individuals are in care before they die. For example, if they die in the first years of care then the preferred formula is always cheaper for the state because state support kicks in later. However, a wider range of examples need to be tested using mortality tables for people with different care tariffs and hence different care needs over the care cycle, and because such comparisons are not always straightforward due to technical complications of having exogenous capital limits.

\section{Interfacing means testing with care savings products}

The Dilnot Commission believed that a cap on care costs would result in a market for insurance products that would cover care costs up to the cap. To date, this has not happened and in our opinion is unlikely to do so. Firstly, the Government is equivocating on the cap and has delayed any final decisions until the next Parliament. Because the cap is set at a relatively high level, the time to reach it is criticised as being too long. Secondly, and partly as a result, there are no indications that "the private insurance market will develop as expected". ${ }^{27}$ The problem of developing a viable market for long-term care insurance has been a long-standing issue even before the Commission had started its work, with very few policies sold. This strongly implies that, if no significant increase in state support is forthcoming and on the assumption that insurance solutions are unlikely to work, then other ways must be found to bring "new" money into the system.

Although the means test offers an important safety net as a funder of last resort, a key concern of this research is that it deters people from saving for care and so potentially crowds out new sources of finance. It does this by creating the risk of a "moral hazard", since people may choose to let the state cover their costs of care rather than provide for themselves. ${ }^{28}$ One suggestion is to introduce hypothecated accredited care savings products whose aim would be to bring new money into the care system. The general principle is that all accredited care savings products should be subject to incentives and financial reward to avoid or offset the means test trap. In other words, it must pay people to save in this way.

\footnotetext{
${ }^{27}$ This view is expressed in a letter by the then care minister, Alistair Burt, to the Chair of the Local Government Association on 17 July 2015. https://www.gov.uk/government/uploads/system/uploads/attachment_data/file/ 446309/Cap_on_care_acc.pdf.

${ }^{28}$ DEMOS (2014).
} 
For this to happen, there needs to be stronger savings incentives that produce additional money rather than just substituting for state expenditure.

Who would buy such products? The older population can be visualised as comprising three groups: (a) self-funders, (b) those that will rely almost wholly on state support and (c) those in between that fall into "no-man's land". On reaching age 65+ for most people, there should be little doubt into which they fall, give or take the odd bequest or windfall. A few may be tempted to buy insurance to cover their long-term risks, but at the moment there are no products on the market, and the only products that were available prior to the Care Act have been discontinued. If the Government would like people to save more for their care, then they must be rewarded in some way.

Self-funders do not, by definition, receive any state support and so saving more may make no difference to them, as they would receive nothing anyway; those reliant on state support can do little to improve their position over time, although they could save in small amounts. Those falling into no-man's land are in a quandary: do they save or not? This group will typically own their own home, have above-average pension income and aboveaverage savings. For the first period in care, they will be self-funders, but their home may be at risk if they are the only survivor and need to go into care or if their savings deplete sufficiently and they qualify for state support.

There are several published examples of hypothecated care savings products. These include Personal Care Savings Bonds (PCSBs), ${ }^{29,30}$ accelerated life insurance products or disability linked annuities. ${ }^{31}$ By this we mean authorised products which are triggered upon a care assessment or by some equivalent mechanism that is a condition of the policy or financial product (e.g. upon reaching a certain age). The idea is that the assets in these products would be disregarded for the purposes of means testing but subject to a limit. As a further possible inducement, its value would be ring-fenced from inheritance tax if a person died without spending it all.

An alternative suggestion would be the creation of a new legal mechanism, which we call "care savings accounts", through which people could set money aside specifically to cover the costs of care in later life. The idea would be to commit portions of a person's current wealth in the form of savings or housing equity or combinations thereof subject to a limit. The advantage of this is that it would enable people with mainly housing wealth to ring-fence some of that wealth before that wealth is bequeathed or spent. A care account could be registered with the tax authorities, for example, at state pension age, and could help slow the growth in state spending on care. Again unused assets in the account could be treated as outside a person's estate for inheritance tax purposes.

Since financial products can be designed that provide either an income stream (such as an annuity) or a lump sum, means testing should be able to accommodate both without disadvantage. The question is therefore what difference disregarding some or all of a person's assets held in a care account would have on the wider care economy, and how much the state and individual would each pay given that the state does not have an

\footnotetext{
${ }^{29}$ Mayhew and Smith (2014).

${ }^{30}$ Personal Care Savings Bonds is a lottery-style savings product which works like National Savings Premium Bonds that pay out prizes but also accrue a low rate of interest.

${ }^{31}$ See Mayhew and Smith (2014); Mayhew et al. (2010).
} 
Table 6 Impact on care funding and state support for a person with protected savings account: case (i) without disregard; case (ii) with disregard

\begin{tabular}{lccccc}
\hline $\begin{array}{l}\text { Year in } \\
\text { care }\end{array}$ & $\begin{array}{c}\text { Cumulative care } \\
\text { payments }(£ s)\end{array}$ & $\begin{array}{c}\text { State support } \\
\text { case }(\mathrm{i})(£ s)\end{array}$ & $\begin{array}{c}\text { Cost to individual } \\
\text { case }(\mathrm{i})(£ s)\end{array}$ & $\begin{array}{c}\text { State support } \\
\text { case }(\text { ii) }(£ s)\end{array}$ & $\begin{array}{c}\text { Cost to individual } \\
\text { case }(\text { ii) }(£ s)\end{array}$ \\
\hline 1 & 18,000 & 0 & 18,000 & 0 & 18,000 \\
2 & 36,000 & 0 & 18,000 & 3,600 & 14,400 \\
3 & 54,000 & 2,700 & 15,300 & 5,580 & 12,420 \\
4 & 72,000 & 5,085 & 12,915 & 6,669 & 11,331 \\
5 & 90,000 & 6,397 & 11,603 & 7,268 & 10,732 \\
6 & 108,000 & 7,118 & 10,882 & 7,597 & 10,403 \\
& Final balance & 21,300 & 86,700 & 30,714 & 77,286 \\
\hline
\end{tabular}

unlimited budget to pay for social care. Below, we develop two examples which are designed to tease out these issues and possible financial effects.

\section{Person with protected capital in a care savings product}

Imagine a person with combined assets of $£ 50,000$ including $£ 10,000$ held in PCSBs. They receive domiciliary care for which the tariff is $£ 18,000$ including living costs. The bonds had been purchased regularly over a long period in small amounts and are now available to spend following a care assessment. There are two cases to consider: (i) the whole $£ 50,000$ counts towards assets for financial assessment purposes or (ii) the $£ 10,000$ in PCSBs are disregarded, as they have been designated as part of their personal care budget.

The results, based on the preferred formula, are shown in Table 6. In case (i), initial assets are worth $£ 50,000$, the state pays $£ 21,300$ and the individual $£ 86,700$ over a 6 -year period as per the example in the "Domiciliary example" section earlier. In case (ii), the overall cost of care including living costs is unchanged, but the state now pays $£ 9,414$ more and the individual $£ 9,414$ less. In case (i), this person would not receive any state support for the first 2 years, with the cost gap being effectively filled by the $£ 10,000$ in PCSBs, which was therefore effectively saved in vain.

In case (ii), they would be treated as if they had $£ 10,000$ less in assets; as a result, state expenditure starts from year two rather than year three. Since the "cost to individual" column excludes the value of the bonds, it means they will have $£ 10,000$ more to spend following a care assessment, plus $£ 9,414$ more in state support over a 6-year cycle. Since the lower capital limit is dependent only on income and the tariff, it would remain at its previous value of $£ 22,222$. If the person dies before 6 years, the corresponding level of state support would reflect the shorter duration of care, but the extra $£ 10,000$ available in savings would be unaffected.

Does this mean there is more money in the system overall? The answer is affirmative in terms of extra state support, which can be considered as a "reward" for saving for one's care. Since PCSBs are triggered following a care needs assessment, it is likely that the money will also be "additional", provided it has not simply displaced other savings that had been spent down before the care assessment. Hence, the challenge should be to find mechanisms that encourage saving for this kind of product. Several areas of personal savings have already demonstrated this effect (e.g. tax free ISA accounts, other tax exemptions on savings deposits or dividends, and tax relief on pension contributions, etc.). 
Table 7 Impact on care funding and state support for a person with a registered account and a 20 per cent disregard: case (i) without disregard; case (ii) with disregard

\begin{tabular}{lccccc}
\hline $\begin{array}{l}\text { Year in } \\
\text { care }\end{array}$ & $\begin{array}{c}\text { Cumulative care } \\
\text { payments }(£ s)\end{array}$ & $\begin{array}{c}\text { State support } \\
\text { case }(i)(£ s)\end{array}$ & $\begin{array}{c}\text { Cost to individual } \\
\text { case }(i)(£ s)\end{array}$ & $\begin{array}{c}\text { State support } \\
\text { case }(\text { ii) }(£ s)\end{array}$ & $\begin{array}{c}\text { Cost to individual } \\
\text { case }(\text { ii) }(£ s)\end{array}$ \\
\hline 1 & 25,000 & 8,333 & 16,667 & 11,667 & 13,333 \\
2 & 50,000 & 10,556 & 14,444 & 12,778 & 12,222 \\
3 & 75,000 & 12,037 & 12,963 & 13,519 & 11,481 \\
4 & 100,000 & 13,025 & 11,975 & 14,012 & 10,988 \\
5 & 125,000 & 13,683 & 11,317 & 14,342 & 10,658 \\
6 & 150,000 & 14,122 & 10,878 & 14,561 & 10,439 \\
& Final balance & 71,756 & 78,244 & 80,878 & 69,122 \\
\hline
\end{tabular}

\section{Registered care account with 20 per cent disregard}

Let us imagine for example a situation in which the Government offered a one-off disregard for anyone with a care account. If the Government offered a 20 per cent disregard to a person with $£ 50,000$ in their care account, then only $£ 40,000$ would count towards the means test and so on. Such a policy would be designed to reduce the moral hazard created by the means test, in that it would reward people for setting money or housing equity aside rather than treating this as a reason for the government to offer less support.

Table 7 provides an example of the difference this could make to out-of-pocket costs over a 6-year care cycle of a person with $£ 50,000$ in assets and $£ 10,000$ p.a. income. The disregard would only apply in the first year: case (i) receives no disregard and case (ii) receives 20 per cent, which means that only $£ 40,000$ rather than the full $£ 50,000$ is taken into account. The results show that both cases are entitled to some state support from the outset, but it can be seen that out-of-pocket costs for case (ii) are $£ 69,122$ on surviving 6 years as compared with $£ 78,244$ in case (i).

The same questions apply to this idea as in the case of hypothecated savings products. Although this example shows that the state could end up paying more, there will be many other examples for which individuals could end up being self-funders especially in the first years of care, and so the balance of costs could tilt away from the state as well as towards it. Again, we believe this will depend on how care accounts are designed and operated. For example, there would almost certainly need to be an age limit (say, age 70) to prevent people from sheltering their assets at or just before the point of needing care.

\section{Concluding reflections}

Means testing is needed because the actual costs of social care frequently exceed the levels that individuals can typically afford from their income. Means testing exists to limit the cost to the state by targeting public support on those with low incomes and savings and so means testing can be thought of as a mechanism for calibrating how much support is due and how much the state can afford. The Care Act (2014) resulted in a new method for calculating state support to replace the present system. The introduction of this method, which includes a cap on care costs, has since been postponed until 2020 on cost grounds, 
and the purpose of this paper has been to use this postponement to review the operation of both the proposed formula and its predecessor, i.e. the current means test.

An analysis of the present and proposed formulae found faults with both, and so a new formula, called the "preferred method", was presented and analysed. It was noted that the proposed and preferred methods are actually part of a family of similarly constructed means tests based on the concept of "affordable care years" (see Annex A). These are defined as the years of care a person could afford to pay for from their own income and assets based on a system of tariffs for different packages of care.

Using this concept, the preferred system puts people into five bands based on their eligibility for state support, A, B, C, D or E. A receives the highest levels of support and E the least; those banded greater than E receive nothing and so are "nil-banded". Under the preferred formula and faced with the same care tariff, they would receive the same level of state support as long as they had the same number of "affordable care years". Under the proposed system, by contrast, a person with the same number of affordable care years would receive more favourable treatment if more of their wealth was in assets. These differences in the treatment of wealth make the preferred formula fairer.

The proposed formula contains an upper capital limit which is designed to protect the tax payer. A problem with capital limits is that they introduce complexity and change behaviour, in this case by encouraging people to spend down or give away their assets in order to stay within them. In the proposed method, a cut-off of $£ 118,000$ will restrict state funding to those with assets below this figure. In the preferred method, by contrast, the upper limit is different for each care tariff. Because it is not based on a single global value, it should discourage the early disposal of assets, since the tariff they receive will not be known in advance. For cost control purposes, we therefore believe a tariff system based on the care package and not an arbitrary upper limit is a better and more logical approach.

The use of tariffs does raise the question of whether they should be set nationally or left to local discretion. We know that open-ended commitments can lead to cost escalation as occurred in the early 1980s, leading to more controls being imposed. However, the Government is open to the idea after allowing local authorities to raise an extra 2 per cent on Council Tax to pay for social care from 2016 which could be used to cover local variations in care costs. Tariffs also require that living costs should be included and we simply note that the state benefit system provides a reference point for this purpose. If there was local discretion, it would need to be made clear how any difference between the national recommended and local tariffs would be funded and, if necessary, voted upon in local elections.

Another advantage of the preferred method over the proposed method was that it removed the need for a lower capital limit. This is because the preferred method has an inbuilt asymptotic mechanism for limiting asset depletion and thus protecting individuals. A key feature is that, instead of there being just one limit, a person's "personal limit" varied according to their income and the tariff. A variable limit was justified on the grounds of whether a person's wealth was high in income or in assets and the degree of protection from the state that would be appropriate in individual cases. The formula for calculating limits was shown to be relatively simple, and it would be straightforward to produce tables showing how long it would take to reach them, e.g. in the form $n$ years to reach $x$ per cent of their value. 
One of the most controversial features of the proposed method is the $£ 72,000$ cap on care costs. A cap is a limit on life-time expenditure on care and is different from a lower capital limit, which is a backstop to prevent further depletion of assets. Contributions towards the cap would be monitored by local authorities and therefore incur additional administrative costs which could be used on front line-care. It was originally intended that the cap would enable insurance companies to offer products protecting people up to the value of the cap. However, to date, no products have emerged based on this feature and it is not difficult to see why. Results presented here show that for a typical range of tariffs it could take years to reach the cap at the level set and so the insured person could be dead long before it is triggered.

For the person contemplating buying such a product, they would be wise first to undertake some financial crystal ball gazing. For a typical person with average savings or assets, it is likely that they would reach their asymptotic capital limit before they reached the cap, so that their actual loss exposure would be much less. For example, consider a person with initial assets of $£ 50,000$, an income of $£ 10,000$ and a tariff of $£ 25,000$ of which care costs are $£ 12,000$. Assuming they survived the 6 years needed to reach the cap, the actual loss exposure over and above their income would only be $£ 18,244$ after taking state support into account. For a person with greater assets than this, buying insurance could still make sense, but the problem of whether it would be value-for-money remains, since it depends on whether they would have benefited from state support if had they died before the cap was reached.

Hence, our main conclusion is that interactions between the cap and the means test cast doubt on whether the cap actually does what it was intended to do. ${ }^{32}$ Our preferred approach is to focus on the more important issue of bringing new money into the care system as part of a wider system of incentives, e.g. should a person who takes out insurance be rewarded in some way such as through tax relief or ring-fencing? The general principle is that the purchase of all accredited care savings products, insurance or otherwise, should be incentivised in some way to offset the means test trap. In addition, it should be possible to incorporate within the incentive structures different means of payment. These could range from pre-funded savings or annuities to payments made after death (e.g. based on the sale of fixed assets from person's estate).

In this research, two illustrative mechanisms were proposed: one based on care-specific savings products such as PCSBs which would be disregarded for means testing purposes and another, which we termed "care savings accounts", which ring-fenced a proportion of their assets until they were needed. In the first case, the individual was rewarded by disregarding the savings worth up to $£ 10,000$ for means testing purposes and, in the second case, by disregarding the value of 20 per cent of their assets. By ring-fencing those assets, the temptation to dispose of them is reduced in return for the prospect of more generous state support if care is needed plus protection from inheritance tax should that be necessary.

Both ideas are intended to open up a debate about how best to do this. Plainly, there is wealth of possibilities and disregards could apply, say, to annuity income as well as to savings, and so it is even more important that income and assets are treated fairly. Because

${ }^{32}$ The Commission on Care and Support originally proposed a cap of $£ 35,000$. 
the public has shown little appetite for saving towards care or protecting itself against the costs, selling to this market has proved very difficult in the past. It means that, although incentives are a necessary condition of success, they may not be sufficient. Because of the postponement of the proposed system until 2020, there is a window of opportunity to consider whether there is a better way to provide state support and encourage greater saving.

To conclude, this research has identified several features of the proposed system which could be adjusted to improve its fairness and operation including the scrapping of limits and the cap. We already know that the reason for postponement of the proposed system was related to concerns over the cost to the public purse and that these concerns have not gone away. This suggests that, as well as revisiting the mean testing formula, steps should be taken to improve incentives to save for care and thereby bring new money into the care economy. Hence, it is suggested that the Government and industry set up a review of how best this can be done by considering and evaluating as many practical variants as possible. The package of changes needed could be seen as part of a "whole systems" approach in which people are rewarded for saving for care in ways that would temper the growth of social care costs in a rapidly ageing population. It is hoped that the suggestions in this paper provide a suitable test bed to pursue these ideas.

\section{Acknowledgements}

The author would like to thank the discussants at a launch event held in December 2016 at the Institute and Faculty of Actuaries, London, two anonymous referees and attendees at a workshop convened by the International Longevity Centre-U.K. held at Care England, London in February 2016.

\section{References}

Appleby, J. (2013) Spending on Health and Social Care Over the Next 50 Years: Why Think Long Term?, London: The Kings Fund, from http://www.kingsfund.org.uk/.

Colombo, F. et al. (2011) Health Wanted? Providing and Paying for Long-Term Care, Paris: OECD Publishing. doi:10.1787/9789264097759-en.

Comas-Herrera, A., Wittenberg, R., Costa-Font, J., Gori, C., di Maio, A., Patxot, C., Pickard, L., Pozzi, A. and Rothgang, H. (2006) 'Future long-term care expenditure in Germany, Spain, Italy and the United Kingdom', Ageing \& Society 26(2): 285-302.

Commission on the Future of Health and Social Care in England (2014) A New Settlement for Health And Social Care-Final Report, London: The Kings Fund, from http://www.kingsfund.org.uk/.

Commission on Funding of Care and Support (2011) Fairer Care Funding: The Report of the Commission on Funding of Care and Support, London: Stationery Office, from http://webarchive.nationalarchives.gov.uk/ 20130221130239/https://www.wp.dh.gov.uk/carecommission/files/2011/07/Fairer-Care-Funding-Report.pdf, accessed 12 Feb 2014.

Costa-Font, J., Wittenberg, R., Patxot, C., Comas-Herrera, A., Gori, C., di Maio A., Pickard, L., Pozzi, A. and Rothgang, H. (2008) 'Projecting long-term care expenditure in four European Union member states: The influence of demographic scenarios', Social Indicators Research, 86(2): 303-321.

Forder, J. (2007) Self-funded social care for older people: An analysis of eligibility, variations and future projections. PSSRU Discussion Paper 2505, London: Commission for Social Care Inspection.

HMSO (1999) With respect to old age: long term care-rights and responsibilities, a report by the Royal Commission on Long Term Care, HMG Cm 4192-1, London: The Stationery Office. 
Karlsson, M., Mayhew, L. and Rickayzen, B. (2007) 'Long term care financing in four OECD countries: Fiscal burden and distributive effects', Health Policy 80(1): 107-134.

Karlsson, M., Mayhew, L., Plumb, R. and Rickayzen B. (2006a) 'Future cost for long term care: Cost projections for long term care for older people in the United Kingdom', Health Policy 75(2): 187-213.

Karlsson, M., Mayhew, L. and Rickayzen, B. (2006b) Investigating the market potential for customised long term care insurance products, Actuarial Research Paper No. 174, London: Faculty of Actuarial Science \& Insurance, City University London.

Kenny, T., Barnfield, J. Daly, L., Dunn, A., Passey, D., Rickayzen, B. and Teow, A. (2016) The Future of Social Care Funding - Who Pays?, Sessional research paper, Institute and Faculty of Actuaries.

Mayhew, L. and Lawrence, D. (2006) 'The costs and service implications of substituting intermediate care for acute hospital care', Health Services Management Research 19(2): 80-93.

Mayhew, L. (2009) 'On the effectiveness of care co-ordination services aimed at preventing hospital admissions and emergency attendances', Health Care Management Science 12(3): 269-284.

Mayhew, L., Karlsson, M. and Rickayzen, B. (2010) 'The role of private finance in paying for long term care', Economic Journal 120(548): F478-F504. http://onlinelibrary.wiley.com/doi/10.1111/j.1468-0297.2010.02388. x/pdf, accessed 18 February 2014.

Mayhew, L. and Smith, D. (2014) 'Personal care savings bonds: A new way of saving towards social care in later life', The Geneva Papers on Risk and Insurance-Issues and Practice 39(3): 668-692.

National Audit Office (2011) Means testing, Report by the Comptroller and Auditor General HC 1464 Session 2010-2012, London: The National Audit Office.

Pickard, L., Comas-Herrera, A., Costa-i-Font, J., Gori, C., di Maio, A., Patxot, C., Pozzi, A., Rothgang, H. and Wittenberg R. (2007) 'Modelling an entitlement to long-term care services for older people in Europe: Projections for long-term care expenditure to 2050', Journal of European Social Policy 17(1): 33-48.

Poole, T. (2006) Funding options for older people's social care, Background paper, London: The Kings Fund, from http://www.kingsfund.org.uk/research/publications/appendices_to.html.

SCIE (2015) Eligibility determination for the Care Act, published by the Social Care Institute for Excellence, from http://www.scie.org.uk/.

Select Committee on Public Service and Demographic Change (2013) Ready for ageing? London: The Stationery Office, from http://www.parliament.uk/business/committees/committees-a-z/lords-select/public-services-committee/reportready-for-ageing/.

Wanless, D. (2006) Securing Good Care for Older People_-Taking a Long-Term View, London: The Kings Fund, from http://www.kingsfund.org.uk/sites/files/kf/field/field_publication_file/securing-good-care-for-older-peoplewanless-2006.pdf.

Wittenberg, R., Pickard, L., Malley, J., King, D., Comas-Herrera, A. and Darton, R. (2008a). Future Demand for Social Care, 2005 to 2041: Projections of Demand for Social Care for Older People in England [online], PSSRU Discussion Paper 2514, from www.pssru.ac.uk/pdf/dp2514.pdf.

Wittenberg, R., Malley, J., Comas-Herrera, A., Fernández, J.-L., King, D., Snell, T. and Pickard, L. (2008b) Future Demand for Social Care, 2005 to 2041: Projections of Demand for Social Care and Disability Benefits for Younger People in England [online], PSSRU Discussion Paper 2512, from www.pssru.ac.uk/pdf/dp2512.pdf. 


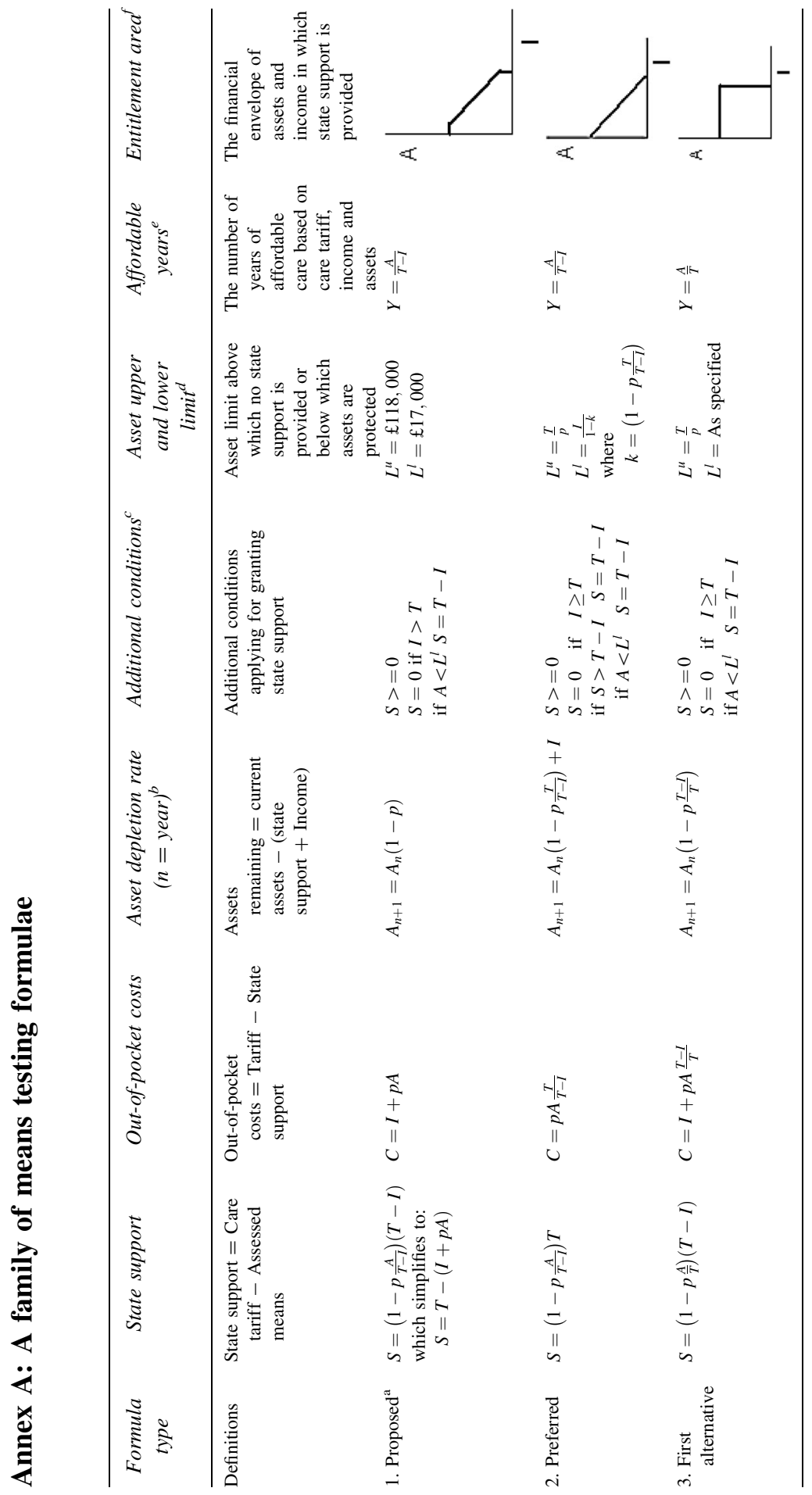




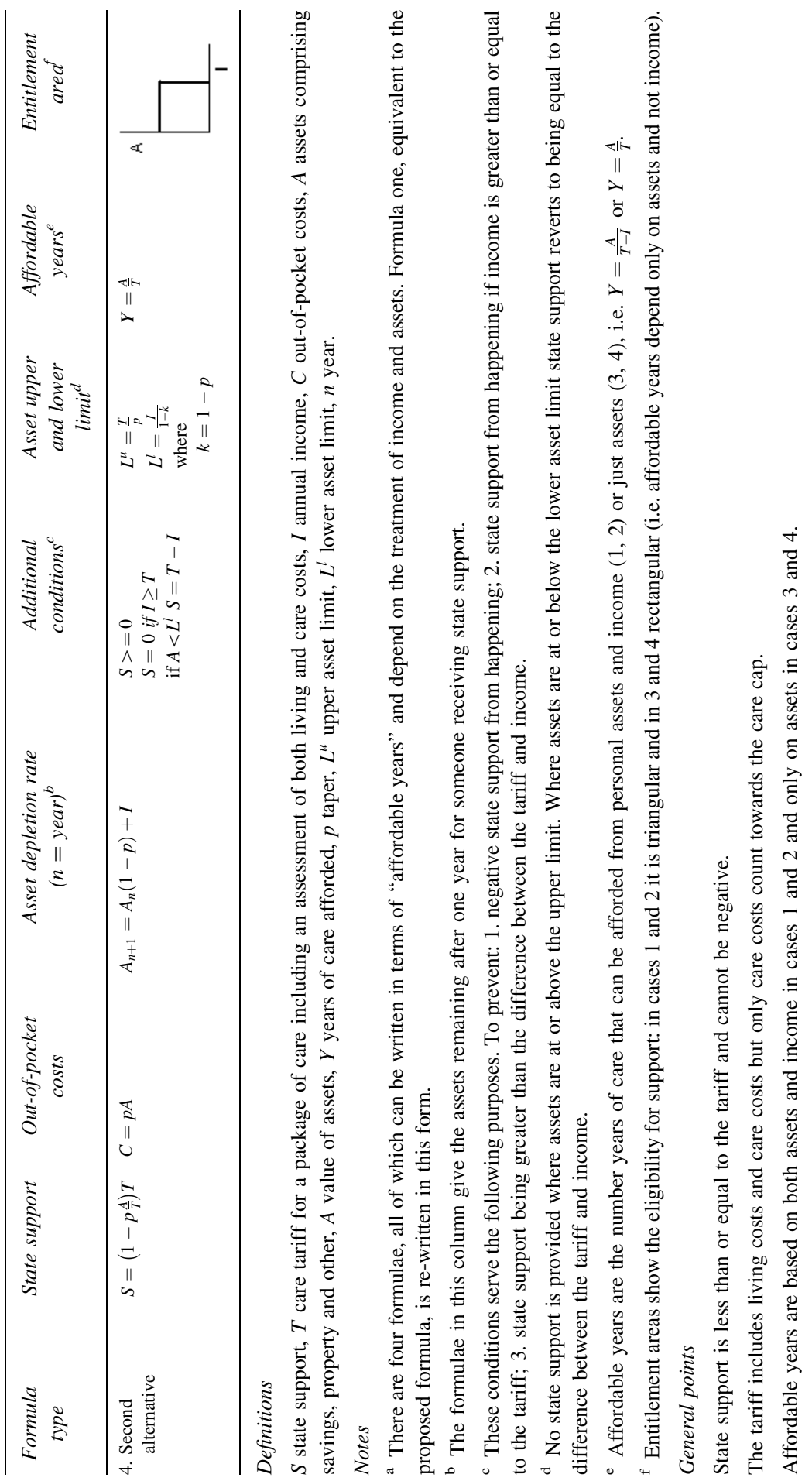




\section{Annex B}

\section{Depletion of assets under the proposed formula}

Under the proposed formula, the lower capital limit currently protects assets worth $£ 17,000$. It can be shown that assets above the capital lower limit deplete at the rate of the taper, currently 0.208 or $£ 1$ a week for every $£ 250$ of capital. Their value in year $n$ is given by

$$
\begin{gathered}
A_{n}=A_{1}(1-p)^{n-1} \\
n=1,2,3,4, \ldots, \text { etc }
\end{gathered}
$$

As $n$ increases, $A_{n}$ trends to zero. To see how it works, consider a person with $£ 50,000$ in assets with care costs of $£ 12,000$ p.a. of which $£ 17,000$ is protected. The percentage of assets remaining at end of year 6 when the cap would be reached given by $100 \times(1-p)^{n-1}=$ $100 \times 0.792^{5}=31$ per cent, where $p$ equals 0.208 . This produces $0.31 \times(£ 50,000-$ $£ 17,000)=£ 10,230$. The retained assets would therefore be worth $£ 10,283+$ $£ 17,000=£ 27,283$ or 54.6 per cent of the original savings.

More generally, the number of years taken to deplete assets such that they are worth $a$ as a proportion of their original value is given by

$$
n=\frac{\ln a}{\ln (1-p)}+1,
$$

where $a=\frac{A_{n}}{A_{1}}$.

For $a$ equal to 0.5 , i.e. 50 per cent of all assets above the lower limit, this equates to 3.97 years.

\section{Depletion of assets under the preferred formula}

If a person's income is less than the tariff, assets will be drawn down in order to pay for care. Under the preferred formula, there is an automatic lower limit below which assets cannot fall. This annex derives that limit and shows that it depends on income and the tariff but not assets.

Provided that income does not exceed the tariff and that $p y<1$, state support is given by

$$
S=T-(1-p y) \times T
$$

This simplifies to

$$
S=T p y,
$$

where $y$ is the years of care afforded or $\frac{A}{T-I}$ and $p$ is the taper.

Starting their second year, in care they will have $A_{1}\left(1-\frac{p T}{T-I}\right)+I$ assets remaining. Let

$$
k=\left(1-\frac{p T}{T-I}\right)
$$


It follows that the assets remaining at the start of year $\mathrm{n}$ are given by

$$
A_{n}=A_{1} k^{n-1}+I k^{0}+I k^{1}+I k^{2}+\cdots+I k^{n-2} .
$$

For $n=2,3,4, \ldots, n$,where $A_{1}$ is the assets at the start of the first year.

For large $n$, the first term based on the depletion of assets reduces to zero. The sum of the remaining terms converges to a constant given by

$$
A_{n}=\frac{I}{1-k} .
$$

In other words, under the preferred method, assets do not run out but level out at a value which is dependent on income, the tariff and the taper. For example, let the tariff equal $£ 25,000$ and Income $£ 10,000$ p.a., and let $p$ the taper equal 0.2. This gives $k=0.6667$ and so the amount of assets remaining after $n$ years (for $n$ large) is $£ 30,000$ as follows:

$$
A_{n}=\frac{£ 10,000}{1-0.6667}=£ 30,000 .
$$

This limit changes according to a person's income and the tariff.

Let $\mathrm{L}$ be the limit and substituting for $\mathrm{k}$, we have

$$
\begin{aligned}
L & =\frac{I}{\left[1-\left(1-\frac{p T}{T-I}\right)\right]} \\
\frac{d L}{d I} & =\frac{1}{p}-\frac{2 I}{p T} .
\end{aligned}
$$

$\mathrm{L}$ is a maximum when $\frac{d L}{d I}=0$ or when $\frac{I}{T}=\frac{1}{2}$; that is, the limit is a maximum when income equals half the tariff. If starting assets are less than $£ 30,000$, they will remain at their current level for the duration of care, so assets below this level are protected. Based on these results, if income is $£ 7,500$, then the lower limit is $£ 26,250$; if it is $£ 12,500$ or half the tariff, it is $£ 31,250$; if income is $£ 15,000$, it is $£ 30,000$.

\section{About the Author}

Les Mayhew is Professor of Statistics at Cass Business School and a former senior Civil servant in the Department of Social Security, HM Treasury and Office for National Statistics.

Open Access This article is distributed under the terms of the Creative Commons Attribution 4.0 International License (http://creativecommons.org/licenses/by/4.0/), which permits unrestricted use, distribution, and reproduction in any medium, provided you give appropriate credit to the original author(s) and the source, provide a link to the Creative Commons license, and indicate if changes were made. 